\title{
Is there a correlation between physicians' clinical impressions and patients' perceptions of change? Use of the Perceived Change Scale with inpatients with mental disorders
}

\author{
Existe correlação entre a mudança percebida pelo médico e a mudança \\ percebida pelo paciente? Uso da Escala de Mudança Percebida em pacientes \\ com transtornos mentais internados
}

\begin{abstract}
Gabriela Pavan, Julia Almeida Godoy, Ricardo Tavares Monteiro, Hugo Karling Moreschi, Eduardo Lopes Nogueira, Lucas Spanemberg*
\end{abstract}

\begin{abstract}
Introduction: Assessment of the results of treatment for mental disorders becomes more complete when the patient's perspective is incorporated. Here, we aimed to evaluate the psychometric properties and application of the Perceived Change Scale - Patient version (PCS-P) in a sample of inpatients with mental disorders.

Methods: One hundred and ninety-one psychiatric inpatients answered the PCS-P and the Patients' Satisfaction with Mental Health Services Scale (SATIS) and were evaluated in terms of clinical and sociodemographic data. An exploratory factor analysis (EFA) was performed and internal consistency was calculated. The clinical impressions of the patient, family, and physician were correlated with the patient's perception of change.

Results: The EFA indicated a psychometrically suitable four-factor solution. The PCS-P exhibited a coherent relationship with SATIS and had a Cronbach's alpha value of 0.856 . No correlations were found between the physician's clinical global impression of improvement and the patient's perception of change, although a moderate positive correlation was found between the patients' clinical global impression of improvement and the change perceived by the patient.

Conclusions: The PCS-P exhibited adequate psychometric proprieties in a sample of inpatients with mental disorders. The patient's perception of change is an important dimension for evaluation of outcomes in the treatment of mental disorders and differs from the physician's clinical impression of improvement. Evaluation of positive and negative perceptions of the various dimensions of the patient's life enables more precise consideration of the patient's priorities and interests.
\end{abstract}

Keywords: Perceived change, mental disorders, psychometric properties, clinical impression.

\section{Resumo}

Introdução: A avaliação dos resultados do tratamento para transtornos mentais torna-se mais completa quando a perspectiva do paciente é incluída. $\mathrm{O}$ objetivo deste trabalho foi avaliar as propriedades psicométricas e a aplicação da Escala de Mudança Percebida - Versão do Paciente (EMP-P) em uma amostra de pacientes internados com transtornos mentais.

Métodos: Um total de 191 pacientes psiquiátricos internados responderam a EMP-P e a Escala de Avaliação da Satisfação dos Usuários com os Serviços de Saúde Mental (SATIS), além de serem avaliados quanto a dados clínicos e sociodemográficos. Foi realizada análise fatorial exploratória (AFE) e calculada a consistência interna. As impressões clínicas do paciente, da família e do médico foram correlacionadas com a mudança percebida pelo paciente.

Resultados: A AFE indicou uma solução de quatro fatores psicometricamente adequada. A EMP-P apresentou uma relação coerente com a SATIS e um alfa de Cronbach de 0,856. Não foi encontrada correlação entre impressão clínica global de melhora pelo médico e mudança percebida pelo paciente, embora uma correlação positiva moderada tenha sido observada entre impressão clínica global de melhora pelo paciente e mudança percebida pelo paciente.

Conclusão: A EMP-P exibiu propriedades psicométricas adequadas em uma amostra de pacientes com transtornos mentais internados. A percepção de mudança pelo paciente é uma importante dimensão para a avaliação de resultados no tratamento de transtornos mentais e difere da impressão clínica de melhora do médico. A avaliação das percepções positivas e negativas das diversas dimensões da vida dos pacientes permite uma análise mais precisa de suas prioridades e interesses. Descritores: Mudança percebida, transtornos mentais, propriedades psicométricas, impressão clínica.

\footnotetext{
* Departamento de Psiquiatria e Medicina Legal e Serviço de Psiquiatria, Hospital São Lucas (HSL), Pontifícia Universidade Católica do Rio Grande do Sul (PUCRS), Porto Alegre, RS, Brazil.

Financial support: none.

Submitted Nov 16 2015, accepted for publication May 27 2016. No conflicts of interest declared concerning the publication of this article.

Suggested citation: Pavan G, Godoy JA, Monteiro RT, Moreschi HK, Nogueira EL, Spanemberg L. Is there a correlation between physicians' clinical impressions and patients' perceptions of change? Use of the Perceived Change Scale with inpatients with mental disorders. Trends Psychiatry Psychother. 2016;38(4):234-
} 241. http://dx.doi.org/10.1590/2237-6089-2015-0077 


\section{Introduction}

The psychiatric care reform took place in Brazil at the end of the 1970s, following the healthcare reform. After psychiatric deinstitutionalization and the restructuring of mental health services, greater emphasis was put on discussions of the quality of services provided and the results achieved. ${ }^{1}$ The World Health Organization (WHO) has highlighted the importance of incorporating evaluation of treatment results as a continuous and ongoing practice to identify opportunities to improve services..$^{2,3}$ This evaluation has been proposed via an integrative approach, which brings together the three parties involved in such services: patients, family members, and professional staff. ${ }^{2}$

A patient's satisfaction survey is a critical indicator of quality. ${ }^{4}$ Treatment results are normally analyzed through objective information on the patient's clinical state prior to and following the therapy applied, ${ }^{5}$ covering elements such as symptomatic improvement, suicide rates and number of hospitalizations. Over the past three decades, users' views have been progressively included using subjective, self-reported measures of their perceptions of the treatment received and of the results obtained. ${ }^{3}$ Communication with the patient makes it easier to identify issues related to the care provided and to develop strategies to improve services. ${ }^{4}$ The idea that improvements (in symptoms and quality of life) have occurred in a patient's life as a result of the treatment received interferes with the relationship between the objective results of the treatment and the level of satisfaction reported by the patient. ${ }^{6}$ However, should there be positive changes that have been identified by the staff but not by the patient, these changes may not impact on the patient's satisfaction with the treatment received, thereby accounting for the poor correlation between these two measures (i.e., the objective and the subjective information collected). ${ }^{7}$ Dropout rates are high in mental health treatment. ${ }^{2,8}$ However, including patients' feedback has increased their satisfaction with treatment, which leads to better participation, reduced dropouts rates and, consequently, fewer future hospital admissions..$^{9,10}$ In this respect, the current literature offers little information on the quality of psychiatric treatment in hospital practices or treatment results. ${ }^{11,12}$

The original version of the Perceived Change Scale (PCS) was constructed by Mercier et al. in Canada. ${ }^{13}$ The PCS was culturally adapted for Brazil in $2009^{3}$ and validated in Portuguese in 2011. ${ }^{6}$ Adequate psychometric qualities have been demonstrated for the PCS's construct validity, convergent validity, internal consistency and temporal stability. The Brazilian version of the PCS includes 19 items, rather than the 20 of the original version. While one of the 19 items assesses how patients see the overall effects of the treatment they have received, the remaining items assess changes to several aspects of their lives (e.g., physical, psychological, and social). Response options are distributed along a threepoint Likert scale, where 1 indicates worse than before; 2 is no change; and 3 is better than before. During the interview, the questions are read out to the patients and the answers are written down by the interviewer. ${ }^{3,6}$ It should be noted that both cultural adaptation and validation of the PCS were performed with psychiatric outpatients within mental health services and that no studies have yet administered the Portuguese PCS to psychiatric inpatients.

Here, we aimed to evaluate the scale's psychometric properties with patients with mental disorders admitted to a psychiatric unit and to assess the suitability of administering the PCS to this patient group. To achieve this, we compared the PCS results against the patients' reports of their own improvement and well-being, as well as against their family members' and doctors' reports. We also assessed the relationship between the patients' perceived change and their treatment satisfaction.

\section{Methods}

\section{Sample and design}

This was a cross-sectional descriptive study. All patients admitted to the Psychiatric Unit of the Hospital São Lucas (UIP/HSL), run by the Pontifícia Universidade Católica do Rio Grande do Sul (PUCRS), over a 20-month period (from May 2014 to September 2015) were included. A total of 247 individuals were invited to participate in this study. Twenty-four patients refused to participate, 17 did not complete the questionnaires and were excluded, 8 patients were excluded because they were unable to understand the instruments, and 7 were excluded for other reasons. The final sample consisted of $191(77.32 \%)$ patients who completed the PCS-P and the Patients' Satisfaction with Mental Health Services Scale (SATIS-BR) and gave their permission for participation in the study by signing the free and informed consent form.

\section{Instruments}

The clinical and sociodemographic questionnaire is a clinician-rated instrument containing sociodemographic questions (such as gender, age, marital status, educational level and type of health insurance) and questions addressing clinical aspects (e.g., number of 
previous hospitalizations, previous psychiatric treatment and initial psychiatric diagnosis).

The Perceived Change Scale - Patient version (PCS-P) consists of 19 items that assess patients' perception about changes in their lives as a result of receiving treatment, with response options arranged along a threepoint Likert scale: with 1 indicating worse than before; 2 no change; and 3 better than before. The scale contains 19 items, a global item that assesses how the patient perceives the results of the treatment received in general and a further 18 items that assess perceived changes in various dimensions of the patient's life (e.g., physical, psychological, and social life). The scale has been translated into Portuguese and validation in Portuguese demonstrated adequate psychometric performance in terms of construct validity, convergent validity, internal consistency, and temporal stability. ${ }^{6}$

The Perceived Change Scale - Family version (PCS-F) is similar to the PCS-P but it is adapted for application with the patient's family. It consists of the same 19 items, worded to assess the family's perception of changes in the patient's life as a result of receiving treatment. The PCS-F uses the same Likert scale as the PCS-P. The reliability, construct validity, and convergent validity of the PCS-F have all been demonstrated. ${ }^{14}$

The SATIS-BR instrument was originally developed by the WHO to assess satisfaction with mental health care in three groups: patients, families, and professionals. The SATIS-BR consists of 13 questions with responses arranged along five-point Likert scales. The higher the average of the scores for patients' responses, the higher their level of satisfaction with the service. Additionally, the final part of the SATIS-BR asks open questions regarding the user's assessment of the service. The SATIS-BR was translated into and validated in Portuguese, with adequate psychometric properties for construct validity, convergent validity, and reliability. ${ }^{15}$

The Clinical Global Impression Scale - Improvement (CGI-I) is a widely-used assessment tool in psychiatry, which is easy to apply and interpret and is available in the public domain. The CGI-I assesses the degree of patient improvement or response to treatment. Scores range from 1 (very much improved) to 7 (very much worse). ${ }^{16}$

\section{Procedures}

Information was obtained from a routine protocol that is initially completed by the physician at the time of patient admission. This protocol consists of information such as the reason for admission, history of current illness, past medical history, family history, medications in use, mental status examination, diagnostic hypotheses, and the usual demographic data (e.g., age, marital status, employment status, religion, and education).

At the time of patient discharge, the doctor who was responsible for the patient during hospitalization answers the remainder of the initial questionnaire, which includes completing the CGI-I. In order to avoid measurement bias (related to patient embarrassment with answering the questionnaire when administered by their doctor), a researcher not directly linked to patient care administers the SATIS-BR, PCS-P and the Clinical Global Impression - Patient (CGI-P). The same is true of the PCS-F and Clinical Global Impression - Family (CGI-F). Therefore, the treating physician was blinded to the patient's and the patient's family's responses, thereby minimizing any potential introduction of bias to the physician's measurement of improvement. All participants were informed about the research objectives and were given assurances that information would be kept confidential, that the interview would not interfere with their treatment, and that there were no right or wrong answers to the questions.

\section{Statistical analysis}

Sociodemographic and clinical data were expressed as means and standard deviations (SD) for continuous variables and as absolute values and percentages for categorical variables. Pearson correlations were calculated to evaluate correlations between factors and total score of the PCS-P. The values were classified as follows: very weak (0.00 to 0.19$)$, weak ( 0.20 to 0.39$)$, moderate $(0.40$ to 0.59$)$, strong $(0.60$ to 0.79 ), or very strong ( 0.80 to 1.00$).{ }^{17}$ Student's t test for independent samples was used to calculate associations between categorical and continuous variables.

An exploratory factor analysis (EFA) with Varimax rotation was performed to test the instrument's factor structure. The criterion used to define the number of factors to be retained was based on the items' eigenvalues, whereby values exceeding 1.0 were retained. A criterion of at least three items with factor loadings above the minimum cutoff was taken into consideration, as were the factor structure of the original instrument and its theoretical interpretability. The Kaiser-Meyer-Olkin (KMO) test was used to measure the adequacy of the sample, with values of $<0.5$ considered inappropriate; values between 0.5 and 0.7 are poor; values between 0.7 and 0.8 are good; values between 0.8 and 0.9 are great; and values above 0.9 are excellent. The reliability of each factor was assessed by calculating Cronbach's alpha values, where 0.7 or higher was considered reliable. The significance level for all tests was 0.05 and 
all analyses were performed using the Statistical Package for the Social Sciences (SPSS) version 20.0.

\section{Ethics considerations}

This study was approved by the Research Ethics Committee at the Pontifícia Universidade Federal do Rio Grande do Sul (protocol number: 1.035.483).

\section{Results}

The final sample comprised 191 inpatients, with a mean age of 46.06 years $(S D=17.08)$, the majority of whom were female $(64.9 \%)$. The main sociodemographic and clinical features are presented in Table 1. Most patients were single or separated $(53.8 \%)$, had more than 8 years of schooling $(69.2 \%)$, and had private health insurance $(53.4 \%)$. The main psychiatric diagnoses were unipolar depression $(24.6 \%)$, bipolar depression $(24.1 \%)$, and personality disorders (18.8\%).

The exploratory factor analysis identified a four-factor solution as the most psychometrically consistent, with the factors explaining $52.42 \%$ of the variance (Table 2). The items were grouped into EFAcomposing factors related to mood and volition (F1, explaining $15.4 \%$ of variance of data), self-esteem and resilience (F2, explaining $14.53 \%$ of variance), somatic symptoms and energy (F3, explaining $12.72 \%$ of variance), and relationships with others (F4, explaining $9.71 \%$ of variance). For this model, sample adequacy indicators were $\mathrm{KMO}=0.876$; Bartlett $=947.48 ; \mathrm{p}<$ 0.001 . All items had factor loadings higher than 0.4 and there were no items with cross-loadings. The internal consistency of the 18 items had a Cronbach's alpha of 0.856 , with values within factors ranging from 0.620 (F4) to 0.767 (F1).

Table 1 - Sociodemographic and clinical data for the entire sample

\begin{tabular}{|c|c|}
\hline Variable & Number $(\%)$, unless stated otherwise \\
\hline Age, years $(n=191)$, mean $(S D)$ & $43.06(17.08)$ \\
\hline Sex, female $(n=191)$ & $124(64.9)$ \\
\hline \multicolumn{2}{|l|}{ Years of education $(n=188)$} \\
\hline Up to 8 years & $58(30.9)$ \\
\hline $9-12$ years & $74(39.4)$ \\
\hline$>12$ years & $56(29.8)$ \\
\hline \multicolumn{2}{|l|}{ Conjugal status $(n=189)$} \\
\hline Single/separated & $103(53.8)$ \\
\hline Married & $71(37.2)$ \\
\hline Widowed & $15(7.9)$ \\
\hline Number of previous hospitalizations ( $n=182$ ) & $2.36(4.08)$ \\
\hline \multicolumn{2}{|l|}{ Health insurance $(n=189)$} \\
\hline SUS (public healthcare system) & $82(42.9)$ \\
\hline Private health insurance & $102(53.4)$ \\
\hline No insurance (self-financed) & $5(2.6)$ \\
\hline \multicolumn{2}{|l|}{ Psychiatric treatment $(n=185)$} \\
\hline Current & $122(65.9)$ \\
\hline Past & $41(22.2)$ \\
\hline No treatment & $22(11.9)$ \\
\hline \multicolumn{2}{|l|}{ Main psychiatric diagnosis $(n=190)$} \\
\hline Unipolar depression & $47(24.6)$ \\
\hline Bipolar disorder & $46(24.1)$ \\
\hline Personality disorders & $36(18.8)$ \\
\hline Psychotic disorders & $21(11.0)$ \\
\hline Substance use/misuse & $14(7.3)$ \\
\hline Others & $26(13.7)$ \\
\hline Length of stay $(n=191)$, mean $(S D)$ & $30.47(16.80)$ \\
\hline \multicolumn{2}{|l|}{ Clinical Global Impression (190), mean (SD) } \\
\hline Improvement & $5.82(1.02)$ \\
\hline Patient & $6.40(1.00)$ \\
\hline Family & $6.34(0.92)$ \\
\hline
\end{tabular}

$\mathrm{SD}=$ standard deviation.

Table 3 shows the means, standard deviations and medians for each item, as well as the factor scores and the total score for the PCS-P. In general, the patients scored better than before for most items, except appetite, physical condition and interest in sex. 
Table 2 - Exploratory factor analysis solution for the Perception of Change Scale - Patient version and Cronbach's alpha values for each of the four factors

\begin{tabular}{|c|c|c|c|c|}
\hline Items & $\begin{array}{c}\text { F1 } \\
\text { Mood/volition }\end{array}$ & $\begin{array}{c}\text { F2 } \\
\text { Self-esteem/resilience }\end{array}$ & $\begin{array}{c}\text { F3 } \\
\text { Somatic/ energy }\end{array}$ & $\begin{array}{c}\text { F4 } \\
\begin{array}{c}\text { Relationship with } \\
\text { others }\end{array} \\
\end{array}$ \\
\hline P2 - Morale or mood & 0.768 & & & \\
\hline P1 - Personal difficulties & 0.719 & & & \\
\hline P5 - Interest in life & 0.635 & & & \\
\hline P15 - Interest in work & 0.496 & & & \\
\hline P16 - Leisure activities & 0.437 & & & \\
\hline P18 - Capacity to assume responsibilities & & 0.671 & & \\
\hline P6 - Resistance to stress & & 0.634 & & \\
\hline P12 - Relationships with family & & 0.598 & & \\
\hline P4 - Self-esteem & & 0.559 & & \\
\hline P3 - Stability of emotions & & 0.523 & & \\
\hline P9 - Sleep & & & 0.716 & \\
\hline P7 - Appetite & & & 0.694 & \\
\hline P10 - Physical condition & & & 0.581 & \\
\hline P17 - Housekeeping chores & & & 0.529 & \\
\hline P8 - Energy level & & & 0.423 & \\
\hline P13 - Relationships with friends & & & & 0.740 \\
\hline P14 - Relationships with people in general & & & & 0.631 \\
\hline P11 - Interest in sex & & & & 0.596 \\
\hline Cronbach's alpha & 0.767 & 0.727 & 0.676 & 0.620 \\
\hline
\end{tabular}

Table 3 - Mean, standard deviation, and median of items, factors and total scores of the Perceived Change Scale - Patient version

\begin{tabular}{|c|c|c|}
\hline Item & Mean (SD) & Median \\
\hline P1 - Personal difficulties & $0.805(0.397)$ & 1 \\
\hline P2 - Morale or mood & $0.863(0.340)$ & 1 \\
\hline P3 - Stability of emotions & $0.894(0.307)$ & 1 \\
\hline P4 - Self-esteem & $0.800(0.401)$ & 1 \\
\hline P5 - Interest in life & $0.873(0.333)$ & 1 \\
\hline P6 - Resistance to stress & $0.773(0.419)$ & 1 \\
\hline P7 - Appetite & $0.463(0.499)$ & 0 \\
\hline P8 - Energy level & $0.742(0.438)$ & 1 \\
\hline P9 - Sleep & $0.631(0.483)$ & 1 \\
\hline P10 - Physical condition & $0.494(0.501)$ & 0 \\
\hline P11 - Interest in sex & $0.231(0.422)$ & 0 \\
\hline P12 - Relationships with family & $0.757(0.429)$ & 1 \\
\hline P13 - Relationships with friends & $0.536(0.499)$ & 1 \\
\hline P14 - Relationships with people in general & $0.678(0.468)$ & 1 \\
\hline P15 - Interest in work & $0.747(0.435)$ & 1 \\
\hline P16 - Leisure activities & $0.668(0.472)$ & 1 \\
\hline P17 - Housekeeping chores & $0.615(0.487)$ & 1 \\
\hline P18 - Capacity to assume responsibilities & $0.742(0.438)$ & 1 \\
\hline F1 - Mood/volition & $3.957(1.409)$ & 5 \\
\hline F2 - Self-esteem/resilience & $3.968(1.324)$ & 4 \\
\hline F3 - Somatic/energy & $2.947(1.510)$ & 3 \\
\hline F4 - Relationship with others & $1.447(0.994)$ & 1 \\
\hline Total score & $12.32(4.071)$ & 13 \\
\hline
\end{tabular}

$\mathrm{SD}=$ standard deviation .

Table 4 shows the results for the analysis of correlations between the four factors of the PCS-P and the total score of the instrument and for the SATIS-BR, the PCS-F total score, the CGI-I, CGI-P and the CGI-F. In general, the correlations between factors were significant, from moderate to strong. The correlations between the factors and the PCS-P total score were either strong (factors 2 and 4) or very strong (factors 1 and 3). The correlation between the PCS-P total score and its factors and SATIS (a correlated, but different construct) were also significant; very weak (factor 4) or weak (factor $1,2,3$ and total score). The correlations between the PCS-P factors and PCS-F total score were significant and weak. There were no significant correlations between the PCS-P factors or total scores and the physician's impression of improvement (CGI-I), whereas the PCS-P exhibited weak (PCS-P factor 2 and PCS-P total score) to moderate (PCS-P factor 1 ) correlations with the CGI-P. There was a very weak correlation between PCS-P factor 2 and the families' clinical impression (CGI-F). 
Table 4 - Correlations between Perception of Change Scale Patient/Family versions total score, factor scores, Patient's Satisfaction with Mental Health Services Scale and the Clinical Global Impression scales

\begin{tabular}{|c|c|c|c|c|c|c|c|c|c|c|}
\hline & PCS-P F1 & PCS-P F2 & PCS-P F3 & PCS-P F4 & PCS-P & SATIS-BR & PCS-F & CGI-I & CGI-P & CGI-F \\
\hline PCS-P 1 & 1 & - & - & - & - & - & - & - & - & - \\
\hline PCS-P 2 & $0.580 *$ & 1 & - & - & - & - & - & - & - & - \\
\hline PCS-P 3 & $0.486^{*}$ & $0.472 *$ & 1 & - & - & - & - & - & - & - \\
\hline PCS-P 4 & $0.362 *$ & $0.408^{*}$ & $0.443^{*}$ & 1 & - & - & - & - & - & - \\
\hline PCS-P & $0.804 *$ & $0.801 *$ & $0.802 *$ & $0.669 *$ & 1 & - & - & - & - & - \\
\hline SATIS-BR & $0.258 *$ & $0.299 *$ & $0.212 *$ & $0.180^{+}$ & $0.309 *$ & 1 & - & - & - & - \\
\hline PCS-F & $0.265 *$ & $0.275^{*}$ & $0.219 *$ & $0.215^{*}$ & $0.327 *$ & 0.109 & 1 & - & - & - \\
\hline CGI-I & 0.036 & 0.011 & -0.090 & -0.049 & -0.030 & -0.014 & 0.127 & 1 & - & - \\
\hline CGI-P & $0.407^{*}$ & $0.377^{*}$ & $0.191^{+}$ & 0.135 & $0.368 *$ & $0.323 *$ & $0.157^{\dagger}$ & $0.292^{+}$ & 1 & - \\
\hline CGI-F & 0.086 & $0.168^{+}$ & 0.068 & 0.028 & 0.118 & 0.072 & $0.343 *$ & $0.323 *$ & $0.432 *$ & 1 \\
\hline
\end{tabular}

CGI-I = Clinical Global Impression - Improvement; CGI-F = Clinical Global Impression - Family; CGI-P = Clinical Global Impression - Patient; PCS-F = Perception of Change Scale - Family version; PCS-P = Perception of Change Scale - Patient version; SATIS = Patient's Satisfaction with Mental Health Services Scale.

$* \mathrm{p}<0.01 ;+\mathrm{p}<0.05$.

\section{Discussion}

In this study we evaluated the psychometric properties of the PCS-P and found that the factor structure revealed by the results of administration to a sample of inpatients with mental disorders was conceptually adequate. The PCS-P exhibited high internal consistency and a consistent correlation with patients' levels of satisfaction with the service. Furthermore, no correlation was found between the clinical impressions of improvement, as evaluated by the physician and the patient's perceived improvement. The most significant correlations were found between clinical impression of improvement and perception of improvement through the PCS-P, both assessed by the patients. To our knowledge, this is the first study using the PCS-P in a sample of patients hospitalized for mental disorders.

The 191 patients included were predominantly middle-aged, single or separated, and female and their main diagnoses were mood, personality, and psychotic disorders. These data are consistent with other Brazilian studies on patients admitted to psychiatric units in general hospitals. ${ }^{18,19}$ On average, the clinical impression of the clinician as assessed with the CGI was that patients had improved slightly, while the patients themselves and their family members perceived moderate improvement, after an average hospital stay of 30 days (a similar length of stay to that of other studies).

The factor structure of the PCS-P identified a more parsimonious psychometric and clinically interpretable solution on a four-factor model, differing from the threefactor structure reported by Bandeira et al. ${ }^{6}$ and from the original study by Mercier et al. ${ }^{13}$ This difference can be attributed to the fact that our sample was composed of inpatients, unlike the other studies conducted to date. This is likely due to restrictions associated with hospital, which can affect patient perceptions, especially in activities that involve contact with others. Moreover, differences between these studies in terms of the composition and number of factors should also be noted. In the study by Bandeira et al., ${ }^{6}$ recreational activity and physical health were included in the same factor, whereas these were grouped into different factors in this study. Additionally, in this study physical health was grouped with other somatic symptoms in the same factor (e.g., sleep, appetite and energy level). We hypothesize that these differences may be due to differences in the origin of the patients included in these studies. Inpatients have more acute symptoms and require more medications than outpatients and are more likely to suffer from side effects of psychotropic drugs.

In our analysis, the item relationship with family was grouped in the same factor as the items ability to take responsibility, stress resistance, stability of emotions and self-esteem, in a factor called self-esteem/resilience. This factor can be thought of as the product of the results of the treatment performed, since improvements in these items reduce problematic behaviors and improve patients' functioning. These improvements are associated with the fact that supervision of problem behaviors is a greater burden to families of psychiatric patients than other aspects, ${ }^{20}$ which supports the idea that a decrease in symptoms facilitates patients' relationships with their families. Items on relationships with friends, relationships with people in general and sexuality were grouped into the same factor (relationship with others). In this case, the condition of admission, which implies deprivation of contact, may have influenced the behavior of the items, since sexuality and contact with others are private.

Regarding satisfaction with the service, we found a positive correlation with the perception of improvement in all four of its factors and total score. This association has been studied and demonstrated elsewhere in recent years. ${ }^{4,6}$ One interesting finding of our study was the absence of significant correlation between change scores perceived by the patient and the physician's 
clinical impression of improvement. Similar results were found in another study, in which positive changes were perceived by professionals but not by patients. ${ }^{7}$ The discrepancy between the patients and physicians' clinical impression of improvement could have important clinical implications. One important implication could be related to lack of perception of improvement by the physician when the patient feels better, which might result in unnecessary changes to treatment. On the other hand, when the physician's assessment is that there has been clinical improvement, but the patient does not feel better, the chances of dropouts and poor treatment compliance significantly increase. It is therefore recommended that the physician should always consider the patient's clinical impression of improvement when making assessments of treatment outcomes.

Furthermore, while the clinical impression evaluated by the family in general also exhibited no correlation with the change perceived by the patient, there was just a weak correlation between the change perceived by the patient and family A study with outpatients ${ }^{11}$ that compared change perceived by the patient with change perceived by the family found that patients and families perceived changes in various aspects of the patients' lives similarly. Our results show only a weak correlation between the perceptions of patients and family members, which may be due to difficulties in patient assessment by the family, since the instrument primarily evaluates observable situations that occur in the day-to-day life of the patient, which is more difficult to assess with the contact deprivation linked to being in the hospital environment.

Unlike the disagreement observed between the clinical impression of improvement assessed by the physician and the changes perceived by the patient, when the assessment of clinical improvement was made by the patient themselves, there were significant correlations with the perceptions of change (a very weak correlation with the energy/somatic symptoms factor; weak correlations with the self-esteem/resilience factor and with the total score; and a moderate correlation with the mood/volition factor). This shows that while the physician's clinical impression may have registered a significant change, it is unable to capture the perceptions of change in different dimensions of patient improvement.

Additionally, the global clinical impression as assessed by the patients correlated mainly with their perceptions of improvement in the mood/volition factor. Items related to this factor had the highest change scores, which is similar to a result reported in a study by Costa et al. ${ }^{11}$ This association could indicate that the patients' clinical global impressions of improvement are mainly associated with changes in perception in the volitional/ humor dimension. Therefore, while a more generic score (such as a global clinical impression) may provide an indicator of clinical improvement, a breakdown of the changes in terms of perceptions assessed by the patient can provide support for interventions that improve their well being, quality of life and satisfaction with care.

This study has certain limitations. First, since it is a cross-sectional study, we are unable to make causal inferences. It is not therefore possible to state, for example, that satisfaction with the service and the perception of improvement have mutual influences. Second, we did not perform a test-retest with the PCS-P to assess its reliability at two time points. However, since the patients' perceptions may truly be different at different times, we believe that test-retest reliability could be compromised with this type of instrument. Third, the sample size was below what would be considered the lower limit for an EFA (200 patients). However, our sample size was very close to that number and our factor solution produced a clinically and psychometrically parsimonious result that would be unlikely to change with the addition of a few more patients. Finally, the patients evaluated were acutely ill, which may have affected their perceptive capacity.

Evaluation of mental health services and their impact on the lives of patients and their families provides social validation of the results of treatment and allows assessment of whether the changes detected by health professionals are consistent with the actual perceptions reported by patients. The PCS-P exhibited adequate psychometric properties for a sample of inpatients with psychiatric disorders and proved to be a simple, userfriendly, and sensitive means for assessment of the overall result of treatment in this environment. Since this instrument reveals positive and negative perceptions of various dimensions of the patient's life, it allows patients' priorities and interests to be considered more precisely. Given the relationship between improvement perceived by the patient and satisfaction with the care received, inclusion of this evaluation as a systematic care practice is likely to contribute to improving the quality of mental health services.

\section{Conclusions}

The original version of the RSCT was translated and adapted into American English following rigorous international standards. The instrument is already available for use, although validation is still ongoing and will be the subject of future studies. 
We believe that this instrument should be especially useful for assessment of conscious countertransferential feelings. Additionally, its translation into English should not only facilitate its use in other countries, it should also facilitate its translation into additional languages.

\section{References}

1. Silva MA da, Bandeira M, Scalon JD, Quaglia MAC. Satisfação dos pacientes com os serviços de saúde mental: a percepção de mudanças como preditora. J Bras Psiquiatr. 2012;61:64-71.

2. Bebbington P. The World Health Report 2001. Soc Psychiatry Psychiatr Epidemiol. 2001:36:473-4.

3. Bandeira M, Calzavara MGP, Costa CS, Cesari L. Avaliação de serviços de saúde mental: adaptação transcultural de uma medida da percepção dos usuários sobre os resultados do tratamento. J Bras Psiquiatr. 2009;58:107-14.

4. Boyer L, Baumstarck-Barrau K, Cano N, Zendjidjian X, Belzeaux $R$, Limousin $S$, et al. Assessment of psychiatric inpatient satisfaction: a systematic review of self-reported instruments. Eur Psychiatry. 2009;24:540-9.

5. Donabedian A. Evaluating the quality of medical care. 1066. Milbank Q. 2005;83:691-729.

6. Bandeira M de B, Andradea MCR, Costab CS, Silva MA da. Percepção dos pacientes sobre o tratamento em serviços de saúde mental: validação da Escala de Mudança Percebida. Psicol Reflex Crit. 2011:24:236-44.

7. Hasler G, Moergeli H, Bachmann R, Lambreva E, Buddeberg C, Schnyder U. Patient satisfaction with outpatient psychiatric treatment: the role of diagnosis, pharmacotherapy, and perceived therapeutic change. Can J Psychiatry. 2004;49:31521.

8. Ribeiro MS, Alves MJM, Vieira EM de M, Silva PM, Lamas CVD-B. Fatores associados ao abandono de tratamento em saúde mental em uma unidade de nível secundário do Sistema Municipal de Saúde. J Bras Psiquiatr. 2008;57:16-22.

9. Hansson L. Outcome assessment in psychiatric service evaluation. Soc Psychiatry Psychiatr Epidemiol. 2001;36:244-8.

10. Priebe S, Gruyters T. Patients' assessment of treatment predicting outcome. Schizophr Bull. 1995;21:87-94.

11. Costa CS, Bandeira M, Cavalcanti RL, Scalon JD. [Perceptions by patients and families towards treatment outcomes in mental health services]. Cad Saude Publica. 2011;27:995-1007.
12. Druss BG, Rosenheck RA, Stolar M. Patient satisfaction and administrative measures as indicators of the quality of mental health care. Psychiatr Serv. 1999;50:1053-8.

13. Mercier L, Landry M, Corbiere M, Perreault M. Measuring client's perception as outcome measurement. In: Roberts AR, Yeage KR. Evidence-based practice manual: research and outcome measures in health and human services. Oxford: Oxford University; 2004. p. 904-9.

14. Bandeira M, Felicio CM, Cesari L. Validation of the Perception of Change Scale - Family Version (EMP-F) as a treatment outcome measure in mental health services. Rev Bras Psiquiatr. 2010;32:283-7.

15. Bandeira M, Silva MA da. Escala de Satisfação dos Pacientes com os Serviços de Saúde Mental (SATIS-BR): estudo de validação. J Bras Psiquiatr. 2012;61:124-32.

16. Guy W. Clinical global impression scale. ECDEU Assessment Manual for Psychopharmacology [Internet]. Rockville: US Department of Health, Education, and Welfare Public Health Service Alcohol, Drug Abuse, and Mental Health Administration. 1976 [cited 2016 Jul 26]. https://archive.org/details/ ecdeuassessmentm1933guyw

17. Evans JD. Straightforward statistics for the behavioral sciences. Pacific Grove: Brooks/Cole Pub; 1996.

18. Dalgalarrondo $P$, Botega NJ, Banzato CE. [Patients who benefit from psychiatric admission in the general hospital]. Rev Saude Publica. 2003;37:629-34.

19. Moreschi HK, Pavan G, Godoy JA, Mondrzak R, Almeida MR de, Pacheco MA, et al. Factors related to positive and negative outcomes in psychiatric inpatients in a General Hospital Psychiatric Unit: a proposal for an outcomes index. Arch Clin Psychiatry (São Paulo). 2015;42:6-12.

20. Barroso SM, Bandeira M, Nascimento E. Sobrecarga de familiares de pacientes psiquiátricos atendidos na rede pública. Rev Psiquiatr Clin. 2007;34:270-7.

\section{Correspondence:}

Gabriela Pavan

Departamento de Psiquiatria e Medicina Legal

Hospital São Lucas, Pontifícia Universidade Católica do Rio Grande do Sul (PUCRS)

Av. Ipiranga, 6690

90610-000 - Porto Alegre, RS - Brazil

E-mail: pavan.gabi@yahoo.com.br 